\section{NADPH-diaphorase expression in the rat jejunum after intestinal ischemia/reperfusion}

\author{
A. Bolekova, ${ }^{1}$ T. Spakovska, ${ }^{1}$ \\ D. Kluchova, ${ }^{1}$ S. Toth, ${ }^{2}$ J. Vesela ${ }^{2}$
}

'Department of Anatomy, Pavol Jozef

Safarik University, Kosice;

2Department of Histology and

Embryology, Pavol Jozef Safarik

University, Kosice, Slovak Republic

\section{Abstract}

The purpose of this study was to analyze the nicotinamide adenine dinucleotide phosphate - diaphorase (NADPH-d) activity in the rat jejunum after a mesenteric ischemia/reperfusion injury. Nitric oxide, synthetised from Larginine by the enzyme nitric oxide synthase, is a nonadrenergic noncholinergic relaxant neurotransmitter of the intestinal smooth muscle. It plays an important role in the process of plasticity after the ischemia/reperfusion injury. Experimental animals were divided in two groups: the control group and the ischemic/reperfusion group, with different period of the reperfusion. The NADPH-d histochemical method has been used as a marker for the nitric oxide synthase. NADPH-d activity has been rapidly decreased in the neurons of both enteric nervous systems in plexuses of the jejunum after $1 \mathrm{~h}$ mesenteric ischemia and $1 \mathrm{~h}$ reperfusion. Differences were predominantly detected in the myenteric plexus; they were seen in change of the neuronal shape, in the arrangement of neurons and in intensity of their staining. The NADPH-d positivity was absent in the intestinal crypts. After $1 \mathrm{~h}$ ischemia and $24 \mathrm{~h}$ reperfusion, the NADPH-d activity was gradually increased, but it was lower in comparison with the control group. On the $30^{\text {th }}$ day following the ischemia/reperfusion there were no changes in NADPH-d positivity compared with the control animals. These results indicated that the jejunal ischemia/reperfusion has affected the neurons of the enteric nervous system of adult rats and resulted in the early decrease of NADPH-d positivity $1 \mathrm{~h}$ of the reperfusion insult. The gradual increasing of NADPH-d activity in $24 \mathrm{~h}$ following the reperfusion could be considered as a result of the plasticity process. On the $30^{\text {th }}$ day after the ischemia/reperfusion all histochemical changes were returned to the control levels.

\section{Introduction}

The digestive tract motility, secretion, and blood flow is regulated by a division of the autonomic nervous system - the enteric nervous system (ENS), that detect the physiological condition of the gastrointestinal tract, integrate information about it and provide outputs to control gut movement. ${ }^{1}$ The ENS is organized into two ganglionated nerve networks: the submucosal plexus (SMP) and the myenteric plexus (MP). The smaller of them, SMP (the Meissner's plexus with autonomic ganglia of the parasympathetic system) stimulates secretion from the epithelial cells of intestinal glands or the Lieberkühn's crypt in the gut lumen and contains sensory cells that communicate with motor neurons of the MP. The larger one, MP (the Auerbach's plexus) is situated between the inner circular and outer longitudinal layer of tunica muscularis and contains multipolar visceral neurons responsible for motility and for mediating the enzyme output of adjacent organs. ${ }^{2,3}$ The ENS represents the highly organized intrinsic innervation of the gastrointestinal tract. Severe disturbances of the ENS function can significantly influence on the life quality or can have acute life-threatening effects. ${ }^{4,5}$

The nitric oxide (NO) signalling pathway is a major nonadrenergic noncholinergic inhibitory transmitter mechanism in ENS and is aimed to be an endothelium-derived relaxant-type factor in the mammalian gut. ${ }^{6} \mathrm{NO}$ is a presumed neurotransmitter of the gastrointestinal tract, it can play an important role in the relaxation of the smooth muscles and is involved in many physiological and pathological processes. ${ }^{7-9}$ The production of NO is indicated immunohistochemically by the demonstration of nitric oxide synthase (NOS), the enzyme responsible for N0 generation. The presence of the constitutive NOS (neuronal and endothelial NOS) may be inferred by positive NADPH-d staining, which is specific for the depiction of nerve structures and blood vessels. ${ }^{10-12}$ The staining of other structures is a non-specific NADPH-d stain that is not equivalent to the presence of NOS. ${ }^{7,10}$ NOS is occurred in $29 \%$ of all nerve cell types of the MP in the small intestine and it selectively regulates the intestinal perfusion. Ninety percent of these NOS neurons are inhibitory motor neurons to the muscle and $10 \%$ are interneurons. ${ }^{13}$ The NADPH-diaphorase (NADPH-d) staining method is widely used in the investigation of the nervous system. ${ }^{14-16}$ The nitrergic myenteric neurons are especially susceptible to the development of neuropathy in functional gastrointestinal disorders. ${ }^{16}$

Previous studies have demonstrated the localization and morphology of the NADPH-d
Correspondence: Dr. Adriana Bolekova, Department of Anatomy, Faculty of Medicine, Pavol Jozef Safarik University, Srobarova 2, 04180 Kosice, Slovak Republic.

Tel. +421.55.6228866.

E-mail: a.bolek@seznam.cz

Key words: jejunum, NADPH-d, histochemistry, nitric oxide synthase, ischemia/reperfusion.

Acknowledgements: this work was supported by Grant no. APVV-0252-07.

Received for publication: 20 April 2011. Accepted for publication: 6 June 2011.

This work is licensed under a Creative Commons Attribution NonCommercial 3.0 License (CC BYNC 3.0).

CC Copyright A. Bolekova et al., 2011

Licensee PAGEPress, Italy

European Journal of Histochemistry 2011; 55:e23 doi:10.4081/ejh.2011.e23

positive neural elements of ENS in different areas of the gastrointestinal tract and in different mammalian species, thereby implying participation of NO in ENS innervations. According to that, there was a correlation between NOS immunoreactivity and NADPH-d staining in all neurons examined. ${ }^{17-19}$ Here, as in many other anatomical tissues, NADPH-d has been demonstrated to be a neuronal NOS..$^{10,20,21}$

In order to detect the plasticity processes in the ENS after ischemia/reperfusion (I/R), this study investigates the presence of NADPH-d activity in the rat jejunum at three various stages after I/R. This histochemical staining technique was used to investigate the distribution of the constitutive NOS (cNOS) in the jejunum of adult rat, to provide the morphological basis of $\mathrm{I} / \mathrm{R}$ injury in the small intestine. This injury is of obvious relevance in such situations where there is an interruption of blood supply to the gut, as in a vascular surgery, strangulated hernias or in the construction of free intestinal graft. ${ }^{22}$

\section{Materials and Methods}

\section{Animal treatment and tissue prepa- ration}

The experimental animals, 60 Wistar male rats, weighting 300-400 g, were housed two to a cage under standard conditions of temperature and illumination, and had free access to food pellets and water. All experiments were conducted in accordance with the Committee for Ethics on Animal Experiments at the Faculty of Medicine, Pavol Jozef Safarik 
University, Kosice, Slovakia, and the experimental protocol was approved by the State Veterinary and Food Administration of the Slovak Republic No. 2843/08-221a. All the experiments were made at the same daily hour and season of the year.

The animals divided into four experimental groups were previously fasted overnight and were anesthetized with the intraperitoneal injection of ketamine (Narketan 10\% a.u.v., Vétoquinol, $60-80 \mathrm{mg} / \mathrm{kg}$ ) and xylazine (Rometar $2 \%$ a.u.v., Bioveta a.s., $8-10 \mathrm{mg} / \mathrm{kg}$ ). Animals from groups R1, R24 and R30 (each group with 14 animals) were subjected after a midline abdominal laparotomy to 1-hour ischemia by total occlusion of the cranial mesenteric artery by atraumatic vascular clamp. This artery is anatomically the major artery supplying the jejunum in the laboratory rat, without any other collateral branches. Immediately after the artery was clamped, the arterial supply and pulsation were completely stopped. During the clamping, the oedematous jejunal intestinal segment was changed in colour from the pale anaemic to haemorrhagic dark reddish, indicating ischemia, clearly demarcated from the intestine with normal blood flow. One hour after the ischemic insult, the vascular clamp was removed, and the affected jejunal segment was reperfused. The immediate restoration of the blood flow was examined visually in changing of intestinal colour, together with subsequent arterial pulsation of the intestinal wall.

The laparotomy was closed and the intestine was reperfused for different periods: 1 hour (R1), 24 hours (R24) or 30 days (R30) after ischemia, respectively. In the sham-operated control group $K(n=18)$, the animals were treated in an identical manner except that they did not undergo clamping of the artery.

After relevant time periods $(1 \mathrm{~h}, 24 \mathrm{~h}$ or 30 d) after ischemia, the abdominal incision was performed and a proximal segment $(1 \mathrm{~cm}$ in length) of jejunum $8 \mathrm{~cm}$ distal to the ligament of Treitz was isolated in and placed immediately in the fixative consisting of $4 \%$ paraformaldehyde and $0.1 \%$ glutaraldehyde buffered with $1 \mathrm{M}$ sodium phosphate, $\mathrm{pH}$ 7.4. The fixative was freshly made up immediately before the experiment.

\section{Histochemical procedure}

Jejunal samples were stayed in the above mentioned solution for $24 \mathrm{~h}$, then $1 \mathrm{~h}$ in ascending concentrations of sucrose (15-30\%) and stored overnight at $4^{\circ} \mathrm{C}$. The sections of the jejunum were cut transversally in a freezing microtome into $30-35 \mu \mathrm{m}$ slides and processed by NADPH-d histochemistry using a technique according to Scherer-Singler et al., modified in our laboratory conditions, as was reported in our previous studies. ${ }^{23,24}$ The sec- tions were incubated for $1 \mathrm{~h}$ at $37^{\circ} \mathrm{C}$ in a solution containing $1.5 \mathrm{mM}$ nitroblue tetrazolium (NBT, N6876, Sigma-Aldrich, St. Louis, MD, USA), $1.0 \mathrm{mM}$ ß-NADPH (NADPH, N1630, Sigma-Aldrich), $10.0 \mathrm{mM}$ monosodium malate (malic acid, M1125, Sigma-Aldrich) and 0.5\% Triton X-100 dissolved in $0.1 \mathrm{M}$ phosphate buffer ( $\mathrm{pH}$ 7.4). As a control for NADPH-d we carried out the processing with the omission of the substrate $\beta$-NADPH in the reaction medium. This was to test endogenous reduction activity in the corresponding blue formazan product. ${ }^{25}$ No residual activity was observed. Following the reaction, the sections were rinsed in $0.1 \mathrm{M}$ phosphate buffer $(\mathrm{pH}$ 7.4), mounted on glass slides, air-dried overnight and finally coverslipped with the mounting medium Entellan (Merck 100869, Whitehouse Station, NJ, USA).

\section{Assessment}

The morphologic appearance of the NADPH-d positive structures in the jejunum ENS was evaluated histologically by the light microscope Olympus CH20. Images were obtained with the Moticam 2300 camera mounted on the microscope Optika B600 TI coupled to a capture board in a computer. Digitalized images were taken using software Motic Images Plus (version 2.0 ML). Morphological changes of NADPH-d positive neurons were evaluated in order to compare the control and $\mathrm{I} / \mathrm{R}$ groups.

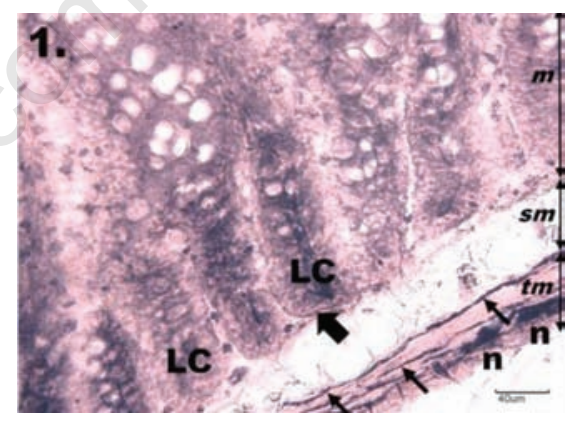

Figure 1. Histological section through jejunum in group $K$. The NADPHdiaphorase positive neurons in the myenteric plexus of jejunum in the control group; tunica mucosa (m), tela submucosa (sm), tunica muscularis (tm). The myenteric plexus is intensely NADPH-d stained, neurons (n) are formed into small ganglions. Rounded or oval shaped neurons are seen located along the nerve fibres (thin arrows) running throughout the tunica muscularis. The mucosa of the jejunum is arranged into regular darkly stained intestinal glands or Lieberkühn's crypts (LC), which are bordered by NADPH-d positive nerve fibres (thick arrow). Scale bar $=\mathbf{4 0} \mu \mathrm{m}$.

\section{Results}

NADPH-diaphorase histochemical procedure results in the deposition of a dark blue formazan reaction product insoluble in water. The cell body, dendritic trees and nerve fibre networks of positive neurons in the rat jejunum were stained in their entirety. NADPH-d activity was generally present in the nerve fibres running throughout the muscular layer and in numerous ganglion cells and processes in the MP. In the SMP they were less numerous than those seen in the MP. In the submucosa, only a few positive nerve fibers were running in the vicinity of the blood vessels, whereas in the muscular layer they were seen quite abundant (Figures 1-4).

In the control group, sham-operated animals $(\mathrm{K})$, the higher NADPH-d activity was found in the MP located in the muscular layer. Neurons were formed into small groups of 3-8 in number. Several NADPH-d-positive neurons were also observed in the SMP. The nerve fibres were seen running surrounding blood vessels both in the muscular layer and lamina propria. The mucosa of the jejunum was arranged into regular intestinal villi and Lieberkühn's crypts (LC). NADPH-d positive staining was present in the depth of LC. The neuronal perikarya were clearly demarcated in plexuses. Neurons of the MP were found in ganglia, which were predominantly elongated with the major axis oriented longitudinally in relation to the circu-

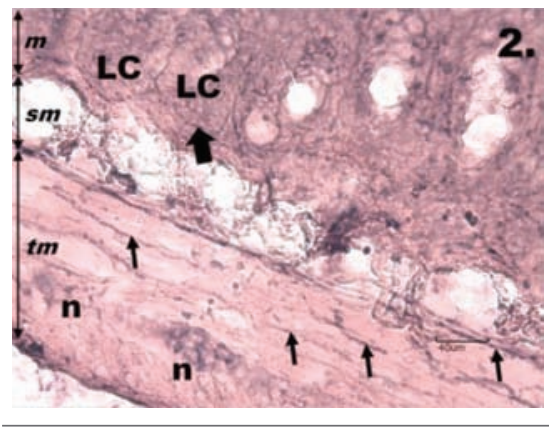

Figure 2. Histological section through jejunum in group $R 1$. One $h$ reperfusion after the ischemia causes a decrease of NADPH-d positivity in the tunica muscularis of the jejunum; tunica mucosa (m) tela submucosa (sm), tunica muscularis (tm). The neurons of myenteric plexus (n) are weakly NADPH-d stained, variable in their shape, size and in the arrangement into the ganglion. The nerve fibres (thin arrows) running throughout the tunica muscularis are interrupted, the neurons are seen with unclear contours of their cell bodies, nuclei, and cytoplasmic processes. The intestinal Lieberkühn's crypts (LC) of the mucosa do not show the NADPH-d positivity, only nerve fibres bordering them are present (thick arrow). Scale bar $=\mathbf{4 0} \mu \mathrm{m}$. 
lar smooth muscle. These rounded or oval shaped neurons were located uniformly with nerve fibres running mainly throughout the circular muscle layer (Figure 1).

The most marked differences in jejunal histomorphology were observed in animals after ischemia and $1 \mathrm{~h}$ of reperfusion (R1). The mucosa of the jejunum has sloughed off compared with the control and irregularly arranged with apparent differences between the intestinal villi; some of them were visible with a total ischemic dissolution in the vicinity to the near-normal villi. NADPH-d activity of both ENS plexuses from the R1 group compared with the $\mathrm{K}$ group has been rapidly decreased in neurons. NADPH-d positivity was distributed mainly in the MP, less in the SMP. Compared with the $\mathrm{K}$ group, differences were predominantly detected in neurons of the MP, which were very variable in a neuronal size, shape and in their arrangement into the ganglion. The neurons had unclearly seen contours of their cell bodies, nuclei, and processes. NADPH-d positivity was absent in the LC, but was abundant in a new vascularised lamina propria surrounded blood vessel (Figure 2).

In animals exposed to ischemia and $24 \mathrm{~h}$ reperfusion (R24), the NADPH-d activity was markedly increased in comparison with the R1 group, but it was still lower than in the $\mathrm{K}$ group. This increasing was noticed in both ENS plexuses as well as and in tunica propria around the blood vessel. The neurons in the MP compared with the R1 group become swollen; they were more intensively NADPH-d stained with greater regularity in shape of cells bodies than those of the $K$ group. The positive staining was not identified at the base of the intestinal villi and the LC (Figure 3). On the 30th day following I/R (R30) all changes noticed in previous experimental groups (R1 and R24) disappeared and the histochemical picture of the jejunum returned to the control level with no differences in NADPH-d positivity compared to the K group. NADPH-d activity was present mainly in neuronal cell bodies and processes in the MP. The discrepancies in the morphology of ENS were not confirmed. The positive NADPH-d staining was again identified at the base of the villi and in the depth of the LC (Figure 4). These results indicated that the jejunal I/R has impaired NOS neurons of the ENS and makes an influence on early decrease in NADPH-d positivity 1 hour following reperfusion. Histomorphological analyses confirmed that $24 \mathrm{~h}$ reperfusion after the ischemia resulted in increasing of NADPH-d staining in the ENS plexuses. Finally, 30 days following the reperfusion, the NADPH-d picture of the jejunal sample has been returned to the control level. This gradual increasing of NADPH-d activity in the R24 group could be considered as a result of the plasticity process.

\section{Discussion}

The presence of NADPH-d staining in the proximal jejunum of the adult rat during $\mathrm{I} / \mathrm{R}$ was studied in this experiment. The NADPH-d histochemistry was used as a marker for the enzyme NOS. NO as an intercellular and endocellular signal molecule has an important role in the physiological processes of the intestine, it regulates muscular contraction and blood circulation of the intestinal endothelia. ${ }^{9}$ The cNOS is widely distributed in the intestine and the presence of the neuronal (nNOS) and endothelial (eNOS) are in accordance with NADPH-d staining. In other tissues, positive staining for NADPH-d is non-specific. ${ }^{7,10}$ The cNOS is critical to normal physiology and development, and inhibition of this enzyme causes a tissue injury. ${ }^{26-28}$

According to the current investigations, except of the cNOS there is an inducible NOS isoform (iNOS) expressed in myenteric neurons, enteric smooth muscle cells, and in the capillary endothelium. ${ }^{29}$ However, all three NOS isoforms are not simultaneously active in the NO synthesis. The presence of different isoforms with similar functions in the same cells might reflect a functional plasticity, in which one NOS isoform can replace another under different pathophysiological conditions. ${ }^{30}$

The NADPH-d reactive neurons, which are inhibitory motor neurons and interneurons, are generally present mostly in the ganglions of the MP, and they are intermingled with

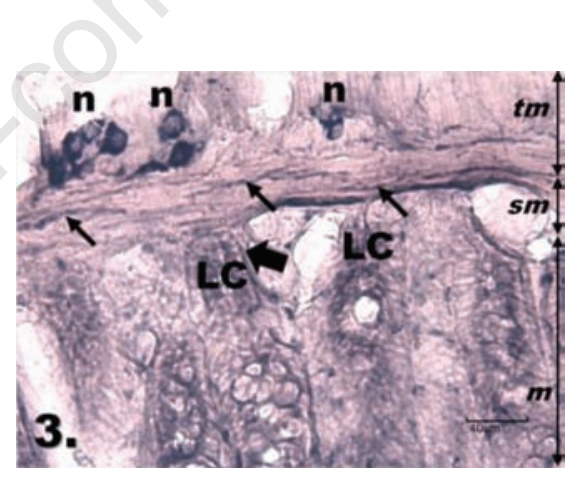

Figure 3. Histological section through jejunum in group R24. Twenty-four hours reperfusion following ischemia makes the increase of NADPH-d positivity in the myenteric plexus of the jejunum compared with group R1; tunica mucosa (m), tela submucosa (sm), tunica muscularis (tm). The neurons (n) in myenteric plexus are clearly contoured and show more regular shape of their cell bodies, stained nerve fibres (thin arrows) are seen running throughout the muscular layer. The Lieberkühn's crypts (LC) are inside moderately NADPH-d stained, bordered by NADPH-d-positive nerve fibres (thick arrows). Scale bar $=\mathbf{4 0} \mu \mathrm{m}$. many other unstained neurons in the small intestine. ${ }^{14}$ The NADPH-d neurons represent a subpopulation of myenteric neurons, which is the only one third of the total number of a myenteric population. ${ }^{19}$ The location of the neurons in ganglia is a common finding in the intestine. The ganglia of the MP are elongated and oriented longitudinally in relation to the circular layer of tunica muscularis. As for the ganglion orientation, a similar distribution was found in the jejunum-ileum in other animals: of mice, guinea pigs, sheep, cats or rabbits. $^{31-34}$ Labelled ganglion cells and nerve fibres were observed in the SMP as well, although they were less numerous than in the MP. In the submucosa, the positive staining was also seen in the blood vessels. The NADPH-d positive neuronal elements of the SMP were located around blood vessels and can regulate the blood flow and secretion of the glands, or it is also possible that they belong to the sensory neurons. ${ }^{30}$

In the mucosa, the nerve fibres were arranged sparsely at the base of the intestinal villi and the LC. In addition to the neuronal staining, there were seen submucosal arterioles with a pattern of small patches of staining unrelated to any perivascular innervation. These findings indicate an extensive neuronal and vascular localization of NO generation potential throughout the wall of the rat intestine, thus providing a structural basis for the functional diversity of $\mathrm{NO}^{35}$

The occlusion and reperfusion of the cranial mesenteric artery is a useful animal model to elucidate the mechanism of gastrointestinal

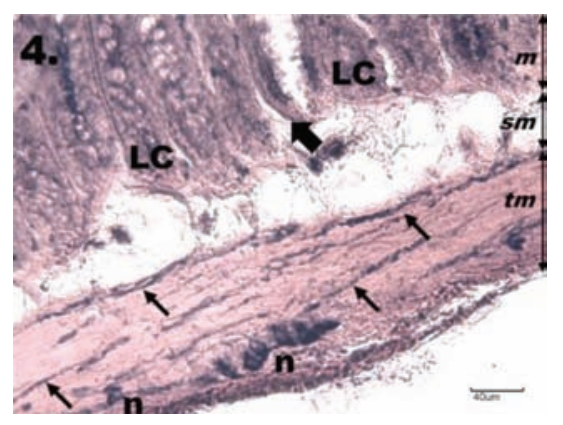

Figure 4. Histological section through jejunum in the group R30. The NADPH-d positivity in the myenteric plexus of jejunum after ischemia and $30 \mathrm{~d}$ reperfusion is seen with no differences in NADPH-d positivity compared with $\mathrm{K}$ group; tunica mucosa (m), tela submucosa (sm), tunica muscularis (tm). NADPH-d activity is present mainly in numerous ganglion cells (n) and nerve fibres (thin arrows) in the tunica muscularis and is also visible in the Lieberkühn's crypts (LC), which are bordered by the NADPH-d-positive nerve fibres (thick arrows). Scale bar $=\mathbf{4 0} \mu \mathrm{m}$. 
injury induced by $\mathrm{I} / \mathrm{R}{ }^{36}$ The ischemic injury itself is a result of the interruption of blood supply. Paradoxically, the restoration of the blood supply causes an additional cell injury that is referred to as a reperfusion injury. ${ }^{37}$ In the intestine, I/R damage to the mucosa and neurons is prominent. The intestine appears to be the most sensitive to I/R injury comparing to other internal organs due to the high susceptibility of enterocytes that are easily injured by episodes of ischemia, and subsequent reperfusion. ${ }^{37}$ Neurons that survive show an evidence of damage for several weeks, but the mucosa quickly repairs. The small intestinal mucosa is a vulnerable system whose epithelium turns over every 2-3 day. The mucosa of the rat jejunum after ischemia and 1 hour of reperfusion were sloughed off compared to the control. This attribute especially at early reperfusion time points have been well documented also in mice. ${ }^{38}$ The NADPH-d positive neurons of the rat jejunum become swollen following $1 \mathrm{~h}$ ischemia and 24 hreperfusion. In two different studies, Rivera et al. showed that the dendrites of NOS immunoreactive neurons distorted and the neurons become swollen following $1 \mathrm{~h}$ ischemia and 24 $\mathrm{h}$ reperfusion also in the guinea pig and mouse ileum. Morphologies of NO neurons were altered early and persisted up to 4 weeks following $\mathrm{I} / \mathrm{R}$, so it is suggests that NO could be involved in the changes. The cell-specific changes occurred without there being significant changes in the relative numbers of neurons of different subtypes. ${ }^{39,40}$

At $24 \mathrm{~h}$ after the initial ischemic insult, the mucosa was as a result of plasticity the most resistant to $\mathrm{I} / \mathrm{R}$ injury. ${ }^{41}$ The MP is also a highly dynamic and adaptive structure and increasing of NADPH-d activity in $24 \mathrm{~h}$ following ischemia (R24) in our experiment confirms this process of plasticity as well.

The I/R injury may contribute to the increasing of intestinal mucosa permeability and may lead to the development of a multiple organ failure. The endotoxins, bacteria and inflammatory mediators are transported particularly by the portal blood and by lymphatic vessels and can cause damage of distant vital organs. ${ }^{42}$

The present results demonstrate that the nitrergic neurons and their processes are widespread in the rat jejunum and they can react in the plasticity and regeneration processes during I/R. This supports the hypothesis that NO in this organ plays an important role not only as a neurotransmitter in the smooth-muscle relaxation or vasodilation in the periphery. It also could be involved in neuronal communication within the enteric nerve plexuses and may influence on different digestive functions. ${ }^{43,44}$

\section{References}

1. Furness JB. The enteric nervous system. 2006, Blackwell Publishing, Malden, MA, USA.

2. Stern M. Neurogenic bowel and bladder in the older adult. Clin Geriatr Med 2006;22: 311-30.

3. Phillips RJ, Powley TL. Innervation of the gastrointestinal tract: patterns of aging. Auton Neurosci 2007;136:1-19.

4. Metzger M. Neurogenesis in the enteric nervous system. Arch Ital Biol 2010;148:7383.

5. Laranjeira C, Pachnis V. Enteric nervous system development: Recent progress and future challenges. Auton Neurosci 2009;151:61-9.

6. Salmhofer H, Neuhuber WL, Ruth P, Huber A, Russwurm M, Allescher HD. Pivotal role of the interstitial cells of Cajal in the nitric oxide signaling pathway of rat small intestine. Morphological evidence. Cell Tissue Res 2001;305:331-40.

7. Bredt DS, Snyder SH. Nitric oxide, a novel neuronal messenger. Neuron 1992;8:3-11.

8. Christopherson KS, Bredt DS. Nitric oxide in excitable tissues: Physiological roles and disease. J Clin Invest 1997;100:2424-9.

9. Chen YM, Qian ZM, Zhang J, Chang YZ, Duan XL. Distribution of constitutive nitric oxide synthase in the jejunum of adult rat. World J Gastroenterol 2002;8: 537-9.

10. Hope BT, Michael GJ, Knigge KM, Vincent SR. Neuronal NADPH di $\neg$ aphorase is a nitric oxide synthase. P Natl Acad Sci USA 1991;88:2811-4.

11. Grozdanovic Z, Baumgarten HG, Bruning G. Histochemistry of NADPH diaphorase, a marker for neuronal nitric oxide synthase, in the peripheral autonomic nervous system of the mouse. Neuroscience. Oxford 1992;48:225-35.

12. Lovásová $\mathrm{K}$, Miklošová $\mathrm{M}$. The enzymatic activity of NADPH-diaphorase in the sciatic nerve of the healthy rat. Folia veterinaria $2000 ; 44: 35-8$.

13. Qu ZD, Thacker M, Castelucci P, Bagyánszki M, Epstein ML, Furness JB. Immunohistochemical analysis of neuron types in the mouse small intestine. Cell Tissue Res 2008;334:147-61.

14. Racekova E, Martoncikova M, Mitruskova B, Cizkova D, Orendacova J: Age related changes of NADPH-diaphorase positivity in the rat rostral migratory stream. Cell Mol Neurobiol 2005;25:1093-105.

15. Kolesar D, Kolesarova M, Pavel J, Davidova A, Marsala J, Lukacova N. Region-specific sensitivity of the spinal cord to ischemia/ reperfusion: the dynamic of changes in catalytic NOS activity. J Physiol Sci 2009;59:97-103.

16. Matsumoto T, Nakane M, Pollock JS, Kuk JE, Forstermann UA. Correlation between soluble brain nitric oxide synthase and NADPH-diaphorase activity is only seen after exposure of the tissue to fixative. Neurosci Lett 1993;155:61-4.

17. Bodi N, Battonyai I, Talapka P, Fekete E, Bagyanszki M. Spatial pattern analysis of nitrergic neurons in the myenteric plexus of the duodenum of different mammalian species. Acta Biol Hung 2009;60:347-58.

18. Cracco C, Filogamo G. Quantitative study of the NADPH-diaphorase-positive myenteric neurons of the rat ileum. Neuroscience 1994;61:351-9.

19. Young HM, Ciampoli D. Transient expression of neuronal nitric oxide synthase by neurons of the submucous plexus of the mouse small intestine. Cell Tissue Res 1998;291:395-401.

20. Lovasova K, Kluchova D, Bolekova A, Dorko F, Spakovska T. Distribution of NADPHdiaphorase and AChE activity in the anterior leaflet of rat mitral valve. Eur J Histochem 2010;54:e5.

21. Kluchova D, Bolekova A, Heichel C, Bron AJ, Kozak I. NADPH-diaphorase expression in the Meibomian glands of rat palpebra in postnatal development. Eur $\mathrm{J}$ Histochem 2010;54:e47.

22. Kong SE, Blennerhassett LR, Heel KA, McCauley RD, Hall JC. Ischemia-reperfusion injury to the intestine. Aust NZJ Surg 1998;68:554-61.

23. Scherer-Singler U, Vincent SR, Kimura $H$, Mc-Geer EG. Demonstration of a unique population of neurons with NADPHdiaphorase histochemistry. J Neurosci Methods 1983;9:229-34.

24. Kluchova D, Klimcik R, Kloc P. Neuronal nitric oxide synthase in the rabbit spinal cord visualised by histochemical NADPHdiaphorase and immunohistochemical NOS methods. Gen Physiol Biophys 2002; 21:163-74.

25. Hope BT, Vincent SR. Histochemical characterization of neuronal NADPHdiaphorase. J Histochem Cytochem 1989; 37:653-61.

26. Sasaki M, Joh T. Oxidative stress and ischemia-reperfusion injury in gastrointestinal tract and antioxidant, protective agents. J Clin Biochem Nutr 2007;40:1-12.

27. Oess S, Icking A, Fulton D, Govers R, Müller-Esterl W. Subcellular targeting and trafficking of nitric oxide synthases. Biochem J 2006;396:401-9.

28. Šmajda B., Tomášová L. Changes in behavior and in hippocampal neurogenesis in prenataly irradiated rats. Physiological Research 2009;58:26-7. 
29. Talapka P, Bodi N, Battonyai I, Fekete E, Bagyanszki M. Subcellular distribution of nitric oxide synthase isoforms in the rat duodenum. World J Gastroenterol 2011;17: 1026-9.

30. Altdorfer K, Feher E, Feher J. Distribution and localization of nitric oxide containing neural elements in the digestive tract. Orv Hetil 1996;137):857-60.

31. Gabella G. On the plasticity of form and structure of enteric ganglia. J Auton Nerv Syst 1990;30:59-66.

32. Miranda-Neto MH, Molinari SL, Natali MRM, SantAna DMG. Regional differences in the number and type of myenteric neurons of the ileum of rats. Arq Neuropsiquiatr 2001;9:54-9.

33. Wilhelm M, Batori Z, Pasztor I, Gabriel R. NADPH-Diaphorase positive myenteric neurons in the ileum of guinea-pig, rat, rabbit and cat: a comparative study Eur J Morphol 1998;36:143-52.

34. Grasa L, Arruebo MP, Plaza MA, Murillo MD. A downregulation of nNOS is associated to dysmotility evoked by lipopolysaccharide in rabbit duodenum. J Physiol
Pharmacol 2008;59:511-24.

35. Nichols K, Staines W, Krantis A. Nitric oxide synthase distribution in the rat intestine: a histochemical analysis. Gastroenterology 1993;105:1651-61.

36. Cerqueira NF, Hussni CA, Yoshida WB. Pathophysiology of mesenteric ischemia/ reperfusion: a review. Acta Cir Bras 2005;20:336-43.

37. Pontell L, Castelucci P, Bagyanszki M, Jovic T, Thacker M, Nurgali $\mathrm{K}$, et al. Structural changes in the epithelium of the small intestine and immune cell infiltration of enteric ganglia following acute mucosal damage and local inflammation. Virchows Arch 2009;455:55-65.

38. Pontell L, Sharma P, Rivera LR, Thacker M, Tan YH, Brock JA, et al. Damaging effects of ischemia/reperfusion on intestinal muscle. Cell Tissue Res 2011;3432:411-9.

39. Rivera LR, Thacker M, Castelucci P, Bron R, Furness JB. The reactions of specific neuron types to intestinal ischemia in the guinea pig enteric nervous system. Acta Neuropathol 2009;118:261-70.

40. Rivera LR, Thacker M, Pontell L, Cho HJ,
Furness JB. Deleterious effects of intestinal ischemia/reperfusion injury in the mouse enteric nervous system are associated with protein nitrosylation. Cell Tissue Res 2011;44:111-23.

41. Osborne DL, Aw TY, Cepinskas G, Kvietys PR. Development of ischemia/reperfusion tolerance in the rat small intestine. J Clin Invest 1994;94:1910-8.

42. Varga J, Stasko P, Toth S, Pristasova Z, Jonecova Z, Vesela J, Pomfy M. Morphological and apoptotic changes in the intestinal mucosa and lung parenchyma after ischaemic/reperfusion injury of the jejunum. Acta Vet Hung 2010;58:243-56.

43. Van Geldre LA, Fraeyman NH, Peeters TL, Timmermans JP, Lefebvre RA. Further characterisation of particulate neuronal nitric oxide synthase in rat small intestine. Auton Neurosci 2004;110:8-18.

44. De Giorgio R, Parodi JE, Brecha NC, Brunicardi FC, Becker JM, Go VLW, et al. Nitric oxide producing neurons in the monkey and human digestive system. J Comp Neurol 1994;342:619-27. 